\title{
Antitumor activity of tripterine via cell-penetrating peptide-coated nanostructured lipid carriers in a prostate cancer model
}

This article was published in the following Dove Press journal:

International Journal of Nanomedicine

4 November 2013

Number of times this article has been viewed

Ling Yuan'

Congyan Liu²

Yan Chen ${ }^{2}$

Zhenhai Zhang ${ }^{2}$

Lei Zhou'

Ding $\mathrm{Qu}^{2}$

'Department of Pharmaceutics, School of Pharmacy, Jiangsu University, Zhenjiang, Jiangsu, ${ }^{2}$ Key Laboratory of New Drug Delivery System of Chinese Materia Medica, Jiangsu Provincial Academy of Chinese Medicine, Nanjing, Jiangsu, People's Republic of China
Correspondence: Yan Chen Key Laboratory of New Drug Delivery System of Chinese Materia Medica, Jiangsu Provincial Academy of Chinese Medicine, 100 Shizi Road, Nanjing, Jiangsu 210028, People's Republic of China

Tel +86 2585608672

Fax +862585637809

Email ychen202@hotmail.com
Background: The purpose of this study was to evaluate the antitumor effect of cell-penetrating peptide-coated tripterine-loaded nanostructured lipid carriers (CT-NLC) on prostate tumor cells in vitro and in vivo.

Methods: CT-NLC were developed to improve the hydrophilicity of tripterine. The antiproliferative effects of CT-NLC, tripterine-loaded nanostructured lipid carriers (T-NLC), and free tripterine in a human prostatic carcinoma cell line (PC-3) and a mouse prostate carcinoma cell line (RM-1) were evaluated using an MTT assay. The advantage of CT-NLC over T-NLC and free tripterine with regard to antitumor activity in vivo was evaluated in a prostate tumor-bearing mouse model. The induced tumor necrosis factor-alpha and interleukin-6 cytokine content was investigated by enzyme-linked immunosorbent assay to determine the effect of CT-NLC, T-NLC, and free tripterine on immune responses. Histologic and TUNEL assays were carried out to investigate the mechanisms of tumor necrosis and apoptosis.

Results: CT-NLC, T-NLC, and free tripterine showed high antiproliferative activity in a dosedependent manner, with an $\mathrm{IC}_{50}$ of $0.60,0.81$, and $1.02 \mu \mathrm{g} / \mathrm{mL}$ in the PC-3 cell line and 0.41 , 0.54 , and $0.89 \mu \mathrm{g} / \mathrm{mL}$ in the RM-1 cell line after 36 hours. In vivo, the tumor inhibition rates for cyclophosphamide, high-dose $(4 \mathrm{mg} / \mathrm{kg})$ and low-dose $(2 \mathrm{mg} / \mathrm{kg})$ tripterine, high-dose $(4 \mathrm{mg} / \mathrm{kg})$ and low-dose $(2 \mathrm{mg} / \mathrm{kg})$ T-NLC, high-dose $(4 \mathrm{mg} / \mathrm{kg})$ and low-dose $(2 \mathrm{mg} / \mathrm{kg})$ CTNLC were $76.51 \%, 37.07 \%, 29.53 \%, 63.56 \%, 48.25 \%, 72.68 \%$, and $54.50 \%$, respectively, showing a dose-dependent pattern. The induced tumor necrosis factor-alpha and interleukin-6 cytokine content after treatment with CT-NLC and T-NLC was significantly higher than that of high-dose tripterine. Moreover, CT-NLC showed the expected advantage of inducing necrosis and apoptosis in prostate tumor cells.

Conclusion: CT-NLC noticeably enhanced antitumor activity in vitro and in vivo and showed dramatically improved cytotoxicity in normal cells in comparison with free tripterine. In summary, CT-NLC could be used as a promising drug delivery system for the treatment of prostate cancer.

Keywords: cell-penetrating peptide, nanostructured lipid carriers, tripterine, prostate cancer, antitumor activity

\section{Introduction}

In recent years, there has been growing interest in identification of a new class of compounds with anticarcinogenic properties from natural sources, including traditional Chinese medicine, in the treatment of human cancers. ${ }^{1-3}$ Tripterine, a bioactive ingredient isolated from the thunder god vine (Tripterygium wilfordii Hook $\mathrm{f}$ ), is a natural proteasome and inhibitor of NF- $\mathrm{KB}$ activity, and shows promising activity against a number of tumor cell lines, including breast cancer, ${ }^{4}$ lung cancer, ${ }^{5}$ hepatocellular carcinoma, ${ }^{6}$ glioma, ${ }^{7}$ melanoma,${ }^{8}$ and prostate cancer. ${ }^{9}$ However, tripterine is poorly 
water-soluble, so is poorly absorbed in the gastrointestinal tract and has low oral bioavailability. At the same time, oral administration of large doses of tripterine can have severe gastrointestinal toxicity, hepatotoxicity, nephrotoxicity, and other side effects. ${ }^{10}$ These deficiencies have limited its further therapeutic application and need to be overcome.

Nanostructured lipid carriers (NLC) represent an improved generation of lipid nanoparticles, and are developed from solid lipid nanoparticle (SLN) systems. They are produced by controlled mixing of solid lipids with spatially incompatible liquid lipids, leading to a specific nanostructure with more imperfections in its crystal structure to accommodate an active drug, and thus achieve higher drug loading capacity. ${ }^{11,12}$ An NLC system minimizes or avoids some of the potential problems associated with SLN, such as poor drug loading and poor stability. Based on their good biocompatibility and stability, high drug loading, and low preparation cost, NLC systems have become promising carriers for improving the oral bioavailability of some of the poorly water-soluble drugs used in traditional Chinese medicine. However, transcellular absorption of lipid nanoparticles by $M$ cells in Peyer's patches or pinocytosis in the gastrointestinal tract after oral administration has hampered the pharmaceutical use of NLC. ${ }^{13}$

Cell-penetrating peptides (CPP) are emerging as attractive drug delivery systems because of their ability to transport a range of cargoes across the cell membrane, ranging from small molecules to proteins and supramolecular particles. ${ }^{1-16}$ For CPP, more must be done to investigate the precise mechanism of action of these molecules, and to improve the efficiency with which they move from the plasma membrane or endomembrane compartments to the cytosol. The same is true regarding the selectivity of CPP. The CPP utilized, the cargo attached, concentration, and cell type all significantly affect the mechanism of internalization. It is now clear that CPP can mediate intracellular delivery via both endocytic and nonendocytic pathways. ${ }^{17-20}$ Most studies have confirmed that CPP has no toxicity or undesirable side effects in most in vivo applications. ${ }^{21,22}$

Previous publications from our laboratory have reported on a CPP-coated tripterine-loaded NLC (CT-NLC) as an oral drug delivery carrier with a new kind of CPP, ie, Ste- $R_{6} L_{2}$. By incorporating CPP into NLC, the new carrier can significantly increase membrane permeability and the oral bioavailability of tripterine.

In our previous work, we have focused mainly on the systematic construction of CT-NLC, such as physicochemical properties, morphology analysis, intestinal absorption, and pharmacokinetic behavior; however, a study of the antitumor efficacy of CT-NLC was lacking. Therefore, in the present study, we evaluated the antitumor effects of CT-NLC on prostate tumor cells in vitro and in vivo, and clarified the underlying antitumor mechanism.

\section{Materials and methods Materials}

Tripterine (purity $>99 \%$ ) was purchased from ZeLang Medicine Technology Co, Ltd (Nanjing, People's Republic of China). Precirol ATO-5 (solid lipid) and Labrafil M 1944CS (liquid lipid) were obtained from Gattefossé (Saint-Priest, France). Poloxamer 188 (Pluronic F68, F68), D- $\alpha$-tocopherol polyethylene glycol succinate 1000, 3-(4,5-dimethylthiazol2-yl)-2,5-diphenyltetrazolium bromide (MTT), and dimethyl sulfoxide were purchased from Sigma-Aldrich (St Louis, MO, USA). Soybean lecithin was supplied by Shanghai Advanced Vehicle Technology Co (Shanghai, People's Republic of China). Fetal bovine serum, F12, and Roswell Park Memorial Institute 1640 medium and trypsin were purchased from Gibco/BRL (Grand Island, NY, USA). Cyclophosphamide was obtained from Jiangsu Hengrui Medicine Co, Ltd (Nanjing, People's Republic of China). All other chemicals were of reagent grade and were used without further purification. Ste-R $\mathrm{L}_{2}$ (Ste-RRRRRRLL, purity $>97 \%$ ) was synthesized by GL Biochem Ltd (Shanghai, People's Republic of China) via a solid-phase synthesis method.

\section{Animals and cell lines}

A human prostatic carcinoma cell line (PC-3) was obtained from KeyGEN Biotech (Nanjing, People's Republic of China) and a mouse prostate carcinoma cell line (RM-1) was obtained from Hanheng Biotech (Shanghai, People's Republic of China). The cells were maintained in Dulbecco's Modified Eagle's Medium or Roswell Park Memorial Institute 1640 medium supplemented with $10 \%$ fetal calf serum, $1 \%$ nonessential amino acids, $100 \mathrm{U} / \mathrm{mL}$ penicillin, and $100 \mu \mathrm{g} / \mathrm{mL}$ streptomycin in a humidified atmosphere of $5 \% \mathrm{CO}_{2}$ at $37^{\circ} \mathrm{C}$.

Male C57BL/6 mice (18-22 g) and Institute of Cancer Research mice were obtained from the SLEK Lab Animal Center (Shanghai, People's Republic of China). The animal experiment protocol was reviewed and approved by the Institutional Animal Care and Use Committee of the Jiangsu Provincial Academy of Chinese Medicine.

\section{Preparation of CT-NLC}

A solvent evaporation method was used to prepare the CTNLC. Precirol ATO-5 and Labrafil M 1944CS (3:1, w/w) were 
chosen as the solid and liquid matrices, respectively. Soybean lecithin and D- $\alpha$-tocopherol polyethylene glycol succinate 1000 were used as emulsifiers. Briefly, lipids, emulsifiers, and tripterine were dissolved in $12 \mathrm{~mL}$ of mixed solvents of acetone and ethanol $(3: 1, \mathrm{v} / \mathrm{v})$ to form the oil phase. Next, $50 \mathrm{~mL}$ of double-distilled water containing $0.5 \mathrm{wt} \% \mathrm{~F} 68$ was used as aqueous phase, in which Ste- $\mathrm{R}_{6} \mathrm{~L}_{2}(30 \mathrm{mg})$ was dissolved. The oil phase was rapidly injected into the stirred aqueous phase $(1,000 \mathrm{rpm})$ at $60^{\circ} \mathrm{C}$, and the resulting suspension was then continually stirred at $400 \mathrm{rpm}$ and $60^{\circ} \mathrm{C}$ for 4 hours. After the organic solvents were removed, the nanoemulsion was stirred in an ice bath for 2 hours to stabilize the CT-NLC. The preparation procedures for T-NLC were the same as that of CT-NLC. The mean particle size and zeta potential of the CT-NLC and T-NLC obtained were measured by Zetasizer (3000 SH, Malvern Instruments Ltd, Malvern, UK).

\section{In vitro cytotoxicity studies}

We used the PC-3 and RM-1 cell lines to investigate the cytotoxicity of CT-NLC, T-NLC, and free tripterine in vitro by MTT assay. The PC-3 cells were seeded into 96-well culture plates at a density of $1 \times 10^{4}$ cells/well, while the RM- 1 cells were seeded at a density of $0.5 \times 10^{4}$ cells/well. The cell lines were then incubated at $37^{\circ} \mathrm{C}$ in a humidified atmosphere with $5 \% \mathrm{CO}_{2}$ for 24 hours. The cells were then treated with the CT-NLC, T-NLC, and free tripterine suspension (dimethyl sulfoxide $<0.1 \%$ ). All samples were performed at equivalent tripterine concentrations of $0.25,0.5,0.75,1.0,1.5$, and $2.0 \mu \mathrm{g} / \mathrm{mL}$. Culture medium was used as a blank control. After 48 hours of incubation, MTT solution $(5 \mathrm{mg} / \mathrm{mL})$ was added to each well and the cells were incubated for another 4 hours. The culture medium was then removed and $100 \mu \mathrm{L}$ of dimethyl sulfoxide was added to each well to dissolve the formazan crystals. The optical density (OD) was measured at $570 \mathrm{~nm}$ using a Multiskan MK3 microplate reader (Thermo Fisher Scientific, Waltham, MA, USA). Cell viability (\%) was calculated using the following formula:

$$
\begin{aligned}
\text { Cell viability }(\%)= & (\mathrm{OD} \text { of test group } / \mathrm{OD} \text { of control } \\
& \text { group }) \times 100
\end{aligned}
$$

The drug concentration causing 50\% inhibition $\left(\mathrm{IC}_{50}\right)$ was calculated using Statistical Package for the Social Sciences version 17 software (SPSS Inc., Chicago, IL, USA).

\section{Acute toxicity test}

The acute toxicity of CT-NLC, administered intragastrically, was estimated according to the Lorke method (1983) in male
Institute of Cancer Research mice. The mice were randomly divided into three groups (each containing ten mice) to receive CT-NLC, T-NLC, or free tripterine $(24 \mathrm{mg} / \mathrm{kg})$. The mice were observed daily over 14 days for mortality, behavioral changes, and other signs of toxicity.

\section{In vivo antitumor effect studies}

Approximately $2 \times 10^{5} \mathrm{RM}-1$ tumor cells were inoculated subcutaneously into the right flank of male C57BL/6 mice weighing 18-22 g. Twenty-four hours after tumor inoculation, designated as day 0 , the mice were weighed and randomly divided into eight groups $(n=8)$ as follows: a negative control (saline) group; a positive control (cyclophosphamide) group; a tripterine $4 \mathrm{mg} / \mathrm{kg}$ group; a tripterine $2 \mathrm{mg} / \mathrm{kg}$ group; a T-NLC $4 \mathrm{mg} / \mathrm{kg}$ group; a T-NLC $2 \mathrm{mg} / \mathrm{kg}$ group; a CT-NLC $4 \mathrm{mg} / \mathrm{kg}$ group; and a CT-NLC $2 \mathrm{mg} / \mathrm{kg}$ group. The control saline or drugs were administered intragastrically every day. Cyclophosphamide $20 \mathrm{mg} / \mathrm{kg}$ was administered by intraperitoneal injection every day. The body weight of the mice and tumor volumes were measured every other day. On day 15, all the mice were weighed and then euthanized by cervical vertebra dislocation, followed by separation and immobilization of the tumor block, thymus, and spleen tissue. Tumor volume was calculated by the formula: $\mathrm{V}=\mathrm{ab}^{2} / 2$, where " $\mathrm{a}$ " is the tumor dimension at the longest point and " $b$ " is the tumor measurement at the widest point. ${ }^{23}$ The antitumor efficacy of each formulation was evaluated by tumor inhibition rate, and was calculated using the following formula:

Tumor inhibition rate $(\%)=[(\mathrm{Wc}-\mathrm{Wt}) / \mathrm{Wc}] \times 100 \%$

where Wt and Wc represent the mean tumor weight of the treated and control groups, respectively.

\section{Cytokine determination}

After 14 days of treatment, blood samples were collected from the retroorbital sinus of each tumor-bearing mouse and centrifuged at $3,000 \mathrm{rpm}$ and $4^{\circ} \mathrm{C}$ for 10 minutes. The supernatants and serum were measured for interleukin (IL)-6 and tumor necrosis factor-alpha (TNF- $\alpha$ ) levels using an enzyme-linked immunosorbent assay kit (KeyGEN Biotech) according to the manufacturer's protocol. OD was measured at $450 \mathrm{~nm}$ by microplate reader.

\section{Histologic assays}

The tumor tissue was isolated, fixed in 10\% formalin, and embedded in paraffin, after which sections $3-5 \mu \mathrm{m}$ in 
thickness were prepared. These thin sections were placed on glass slides, deparaffined in xylen, and dehydrated in graded alcohols. The slides were then stained with hematoxylin and eosin. Later, all the slides were observed under a microscope (ECLIPSE55i, Nikon, Tokyo, Japan).

\section{TUNEL assay}

Tumor tissue fixed with 10\% paraformaldehyde solution was embedded in paraffin and assayed for apoptosis by terminal deoxynucleotidyl transferase (TdT)-mediated dUTP nick end labeling (TUNEL) staining using an apoptotic cell detection kit (KeyGEN Biotech) following the manufacturer's directions. Positive cells (indicated by black arrows) and the total number of cells were counted in ten randomly selected microscopic fields (400× magnification) for each tumor tissue sample. The apoptosis index (AI) was then calculated according to the following formula:

$$
\mathrm{AI}=\text { number of positive cells/total number of cells. }
$$

\section{Statistical analysis}

Statistical analysis was done using Statistical Package for the Social Sciences version 17 software. All the results were expressed as the mean \pm standard deviation. Analysis of variance and the Student's $t$-test were used to evaluate statistical significance. A value of $P<0.05$ was considered to be statistically significant.

\section{Results}

Characterization of CT-NLC and T-NLC

Characterization of the prepared CT-NLC and T-NLC had been determined in a previous study, prior to the present investigation of the antitumor activity of CT-NLC and T-NLC. ${ }^{24}$ Transmission electron microscopy showed that the nanoparticles were spherical. The particle size of the CT-NLC and T-NLC was $126.7 \pm 9.2 \mathrm{~nm}$ and $102.4 \pm 12.8 \mathrm{~nm}$, respectively. The zeta potential of the CT-NLC and T-NLC was $28.7 \pm 3.4 \mathrm{mV}$ and $-26.2 \pm 2.7 \mathrm{mV}$, respectively, and the entrapment efficiency was $72.64 \% \pm 1.37 \%$ and $74.64 \% \pm 0.87 \%$.

\section{Effects of CT-NLC on inhibition of PC-3 and RM-I cell growth}

The cytotoxicity of CT-NLC, T-NLC, and free tripterine was subsequently monitored in PC-3 and RM-1 cells using the MTT assay. Both formulations and free tripterine significantly inhibited the growth of PC-3 and RM-1 cells. As shown in Figures 1 and 2, both formulations and free tripterine showed concentration-dependent cytotoxicity, and the cytotoxicity of the formulations was significantly higher than that of tripterine suspension at all concentrations used. Moreover, CT-NLC had the greatest cytotoxic effect compared with tripterine and T-NLC. As can be seen in Table 1, the $\mathrm{IC}_{50}$ values of the tripterine suspension, T-NLC,

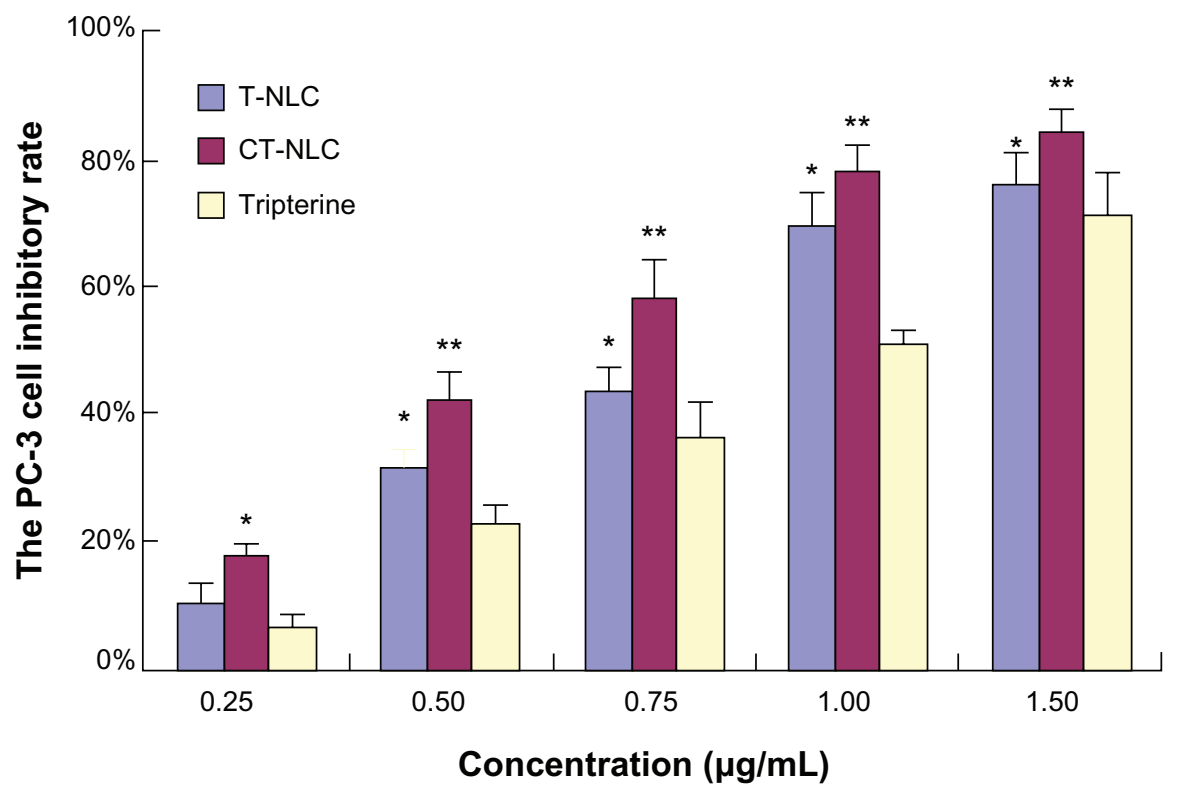

Figure I PC-3 cell inhibitory rate using CT-NLC, T-NLC, and free tripterine at different concentrations after 48 hours by MTT assay.

Notes: Data represent the mean \pm standard deviation $(n=6)$. $* P<0.05 ; * * P<0.01$ versus tripterine.

Abbreviations: T-NLC, tripterine-loaded nanostructured lipid carrier; CT-NLC, cell-penetrating peptide-coated T-NLC. 


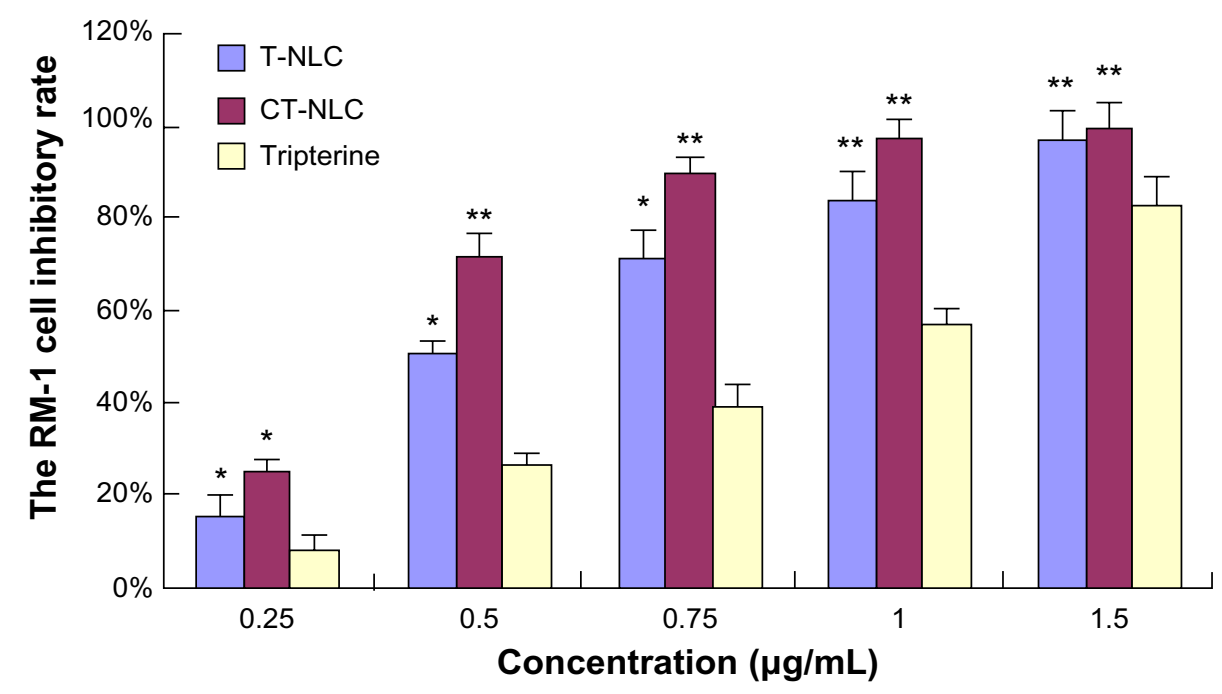

Figure 2 RM-I cell inhibitory rate using CT-NLC, T-NLC, and free tripterine at different concentrations after 48 hours by MTT assay. Notes: Data represent the mean \pm standard deviation $(n=6)$. $* P<0.05 ; * * P<0.01$ versus tripterine.

Abbreviations: T-NLC, tripterine-loaded nanostructured lipid carrier; CT-NLC, cell-penetrating peptide-coated T-NLC.

and CT-NLC after 48 hours of incubation were $0.88 \pm 0.08$, $0.64 \pm 0.05$, and $0.55 \pm 0.07 \mu \mathrm{g} / \mathrm{mL}$ for PC-3 cells and $0.79 \pm 0.04,0.49 \pm 0.03$, and $0.39 \pm 0.02 \mu \mathrm{g} / \mathrm{mL}$ for RM- 1 cells, respectively. The $\mathrm{IC}_{50}$ values for CT-NLC and T-NLC were lower than that of the tripterine suspension; the $\mathrm{IC}_{50}$ value of CT-NLC was the lowest, accounting for the higher antitumor activity of CT-NLC.

\section{Acute toxic effects of CT-NLC in mice}

No visible symptoms of toxicity, such as weight loss, vomiting, or diarrhea, were observed in mice treated with the tripterine suspension, T-NLC, or CT-NLC at an oral dose of $24 \mathrm{mg} / \mathrm{kg}$. The estimated $\mathrm{LD}_{50}$ values for the tripterine suspension, T-NLC, and CT-NLC were higher than $24 \mathrm{mg} / \mathrm{kg}$. Therefore, we concluded that there were no acute toxic effects at an oral dose of $24 \mathrm{mg} / \mathrm{kg}$, and selected $4 \mathrm{mg} / \mathrm{kg}$ (high dose) and $2 \mathrm{mg} / \mathrm{kg}$ (low dose) as the oral dose to be used in the subsequent in vivo experiment.

Table I IC ${ }_{50}$ values for tripterine, T-NLC, and CT-NLC on PC-3 cells and RM-I cells after 48 hours by MTT assay

\begin{tabular}{lll}
\hline Group & $\mathrm{IC}_{50}(\mu \mathrm{g} / \mathrm{mL})$ & \\
\cline { 2 - 3 } & $\mathbf{P C}-3$ cells & RM-I cells \\
\hline Tripterine & $0.88 \pm 0.08^{\dagger}$ & $0.79 \pm 0.04^{\dagger}$ \\
T-NLC & $0.64 \pm 0.05^{*}$ & $0.49 \pm 0.03^{*}$ \\
CT-NLC & $0.55 \pm 0.07^{*, \dagger}$ & $0.39 \pm 0.02^{*, \dagger}$ \\
\hline
\end{tabular}

Notes: Data represent the mean \pm standard deviation. ${ }^{*} \mathrm{P}<0.05$ versus tripterine; ${ }^{\dagger} \mathrm{P}<0.05$ versus $\mathrm{T}-\mathrm{NLC}$.

Abbreviations: T-NLC, tripterine-loaded nanostructured lipid carriers; CT-NLC, cell-penetrating peptide-coated T-NLC; $I C_{50}$, half-maximal inhibitory concentration.

\section{In vivo antitumor effects}

As shown in Figure 3A, tumor volumes in the saline control group were excessively enlarged (approximately 1,500 $\mathrm{mm}^{3}$ ) on day 14 , while tumor growth was significantly inhibited by the free tripterine and formulations of tripterine. At the end of the experiment, tumor volumes in mice treated with CTNLC (4 mg/kg) and T-NLC (4 mg/kg) were $375.6 \pm 130.8 \mathrm{~mm}^{3}$ and $497.9 \pm 239.6 \mathrm{~mm}^{3}$, respectively, decreased the growth of tumors significantly $(P<0.01)$ by $57.2 \%$ and $43.7 \%$ compared with that of the free tripterine suspension group $(884.3$ $\left.\pm 197.2 \mathrm{~cm}^{3}\right)$. CT-NLC had a favorable antitumor effect, and there was no statistically significant difference between the CT-NLC group (4 mg/kg) and the cyclophosphamide group. Compared with the saline control group, the CT-NLC group started to show marked inhibition of tumor growth by day $8(P<0.01)$, with no significant adverse effects, such as a decrease in body weight (Figure 4). Comparison of tumor inhibition rates in the treatment groups yielded the following results: cyclophosphamide $>$ CT-NLC $4 \mathrm{mg} / \mathrm{kg}>$ T-NLC $4 \mathrm{mg} / \mathrm{kg}>$ CT-NLC $2 \mathrm{mg} / \mathrm{kg}>$ T-NLC $2 \mathrm{mg} / \mathrm{kg}>$ free tripterine $4 \mathrm{mg} / \mathrm{kg}>$ free tripterine $2 \mathrm{mg} / \mathrm{kg}$ (Figure 3B). Further, the tumor inhibition rate in the CT-NLC group (4 mg/ $\mathrm{kg}$ ) versus the blank control group was $72.68 \% \pm 6.7 \%$, which was 1.14-fold and 1.96-fold higher than that of the T-NLC and free tripterine groups, respectively. These results indicate that CT-NLC and T-NLC had a greater antitumor effect than free tripterine, in particular CT-NLC.

As shown in Figure 4, after 14 days of treatment, a progressive and irregular decrease in mean body weight 

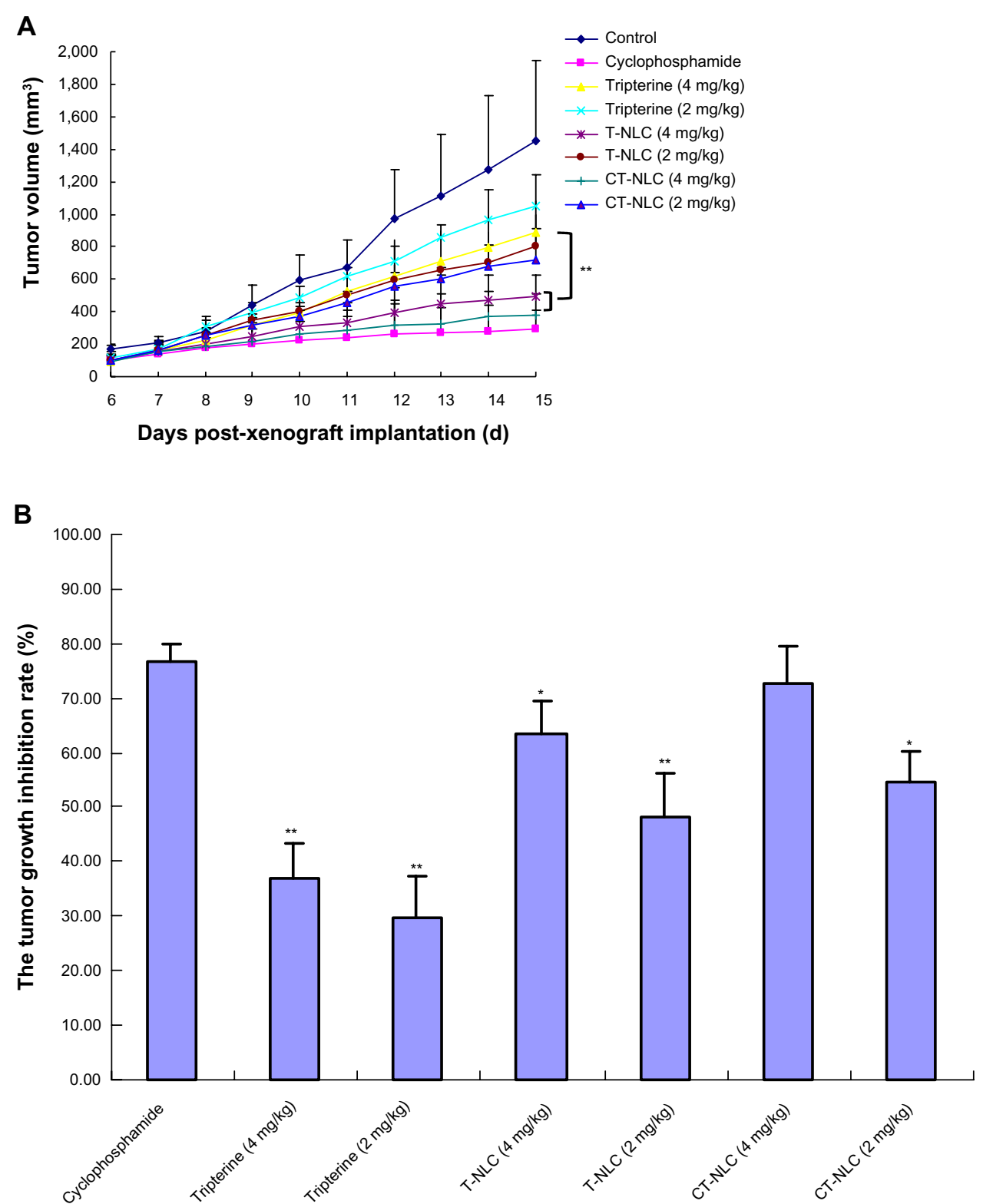

Figure 3 In vivo anticancer activity of CT-NLC, T-NLC, and free tripterine. (A) Change in tumor volume over the course of treatment. (B) Calculated inhibition rate of tumor growth after 14 days of treatment.

Notes: Data represent the mean \pm standard deviation $(n=8)$. $* p<0.05 ; * * p<0.0$ I versus CT-NLC $4 \mathrm{mg} / \mathrm{kg}$.

Abbreviations: T-NLC, tripterine-loaded nanostructured lipid carriers; CT-NLC, cell-penetrating peptide-coated T-NLC.

was noted in all groups, but less so in the CT-NLC and T-NLC groups. Significant weight loss was found in animals treated with cyclophosphamide and in those treated with the free tripterine suspension, and was much greater than that induced by CT-NLC or T-NLC $(4 \mathrm{mg} / \mathrm{kg}, P<0.05)$ and CT-NLC $(2 \mathrm{mg} / \mathrm{kg}, P<0.05)$. In contrast, mice treated with the tripterine formulations gained weight during the course of treatment.

We also examined the effect of CT-NLC on the spleen and thymus index in C57BL/6 mice. As shown in Table 2, the spleen and thymus index for the free tripterine group and the tripterine formulation groups were all decreased compared with the saline control group, but were significantly higher than in the cyclophosphamide group $(P<0.05)$. The spleen and thymus index for the CT-NLC and T-NLC groups was slightly higher than for the high-dose tripterine suspension group, but there was no significant difference in this regard $(P>0.05)$.

\section{Effect of CT-NLC on TNF- $\alpha$ and IL-6 levels}

As expected, treatment with cyclophosphamide and tripterine suspension $(4 \mathrm{mg} / \mathrm{kg}$ ) significantly decreased levels 


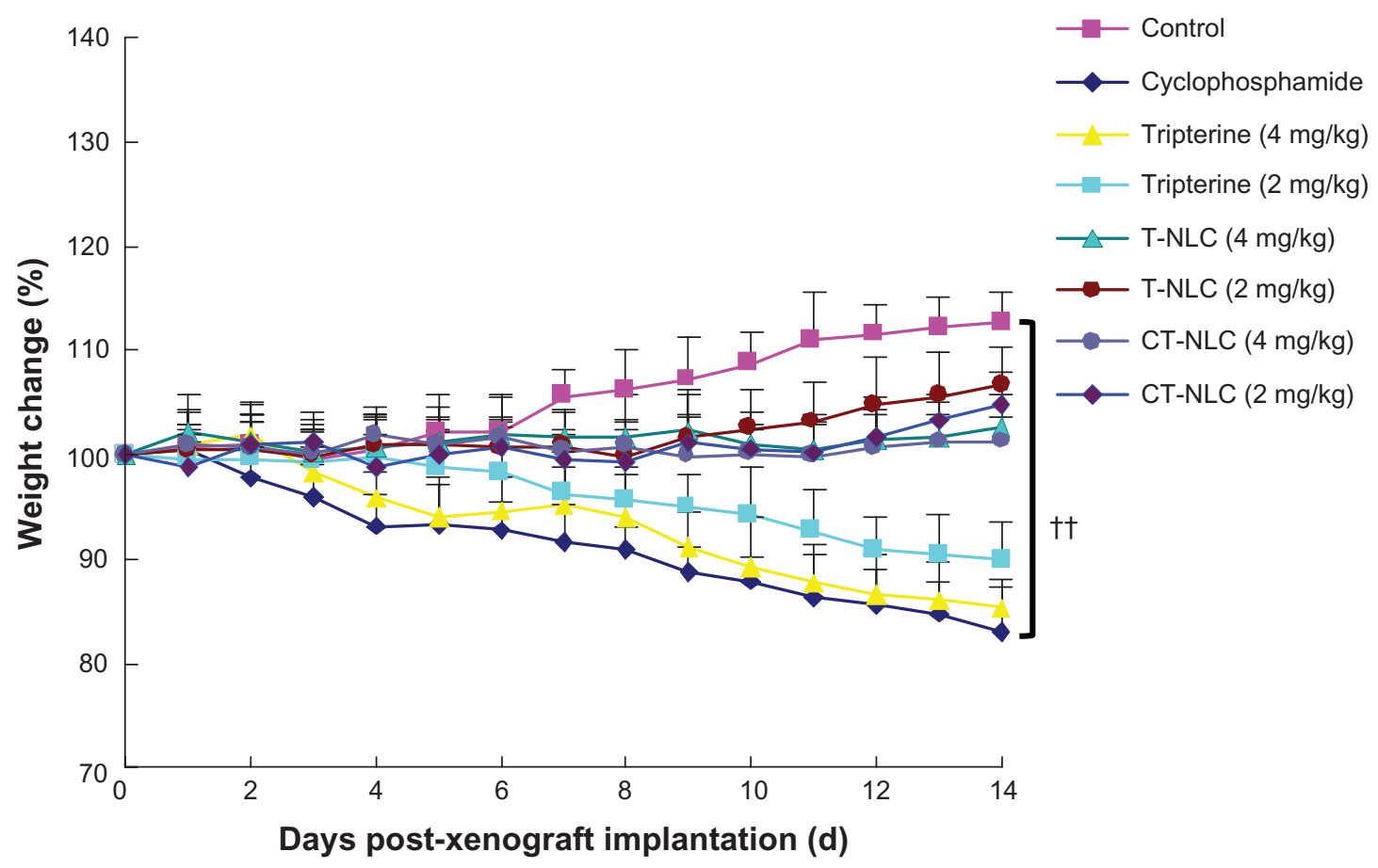

Figure 4 Change in body weight in each treatment group.

Notes: Data represent the mean \pm standard deviation $(n=8)$. ${ }^{t+} p<0.0$ I versus control.

Abbreviations: T-NLC, tripterine-loaded nanostructured lipid carriers; CT-NLC, cell-penetrating peptide-coated T-NLC.

of the proinflammatory cytokines TNF- $\alpha$ and IL- 6 in comparison with the high levels of TNF- $\alpha$ and IL- 6 detected in control mice (Figure 5). However, the TNF- $\alpha$ level in the CT-NLC group was significantly increased compared with the cyclophosphamide and tripterine suspension $(4 \mathrm{mg} / \mathrm{kg})$ groups $(P<0.01)$, and the level of IL-6 in the CT-NLC group was significantly increased compared with the cyclophosphamide group $(P<0.01)$ and the tripterine $4 \mathrm{mg} / \mathrm{kg}$ suspension group $(P<0.05)$. Consequently, the CT-NLC and T-NLC treatment groups showed significantly decreased anti-immunity activity compared with the free tripterine group.

Table 2 Thymus and spleen index in mice

\begin{tabular}{lll}
\hline Group & $\begin{array}{l}\text { Thymus index } \\
(\mathbf{m g} / \mathbf{g})\end{array}$ & $\begin{array}{l}\text { Spleen index } \\
(\mathbf{m g} / \mathbf{g})\end{array}$ \\
\hline Control & $2.18 \pm 0.19^{\dagger \dagger}$ & $5.32 \pm 0.45^{\dagger \dagger}$ \\
Cyclophosphamide & $1.23 \pm 0.17^{* *}$ & $3.54 \pm 0.25^{* *}$ \\
Tripterine $4 \mathrm{mg} / \mathrm{kg}$ & $1.81 \pm 0.18^{* *,+\dagger}$ & $4.64 \pm 0.26^{* *,+\dagger}$ \\
Tripterine $2 \mathrm{mg} / \mathrm{kg}$ & $2.08 \pm 0.15^{\dagger \dagger}$ & $4.97 \pm 0.24^{*,+\dagger}$ \\
T-NLC $4 \mathrm{mg} / \mathrm{kg}$ & $1.97 \pm 0.18^{* *,+\dagger}$ & $4.73 \pm 0.34^{*,+\dagger}$ \\
T-NLC $2 \mathrm{mg} / \mathrm{kg}$ & $2.10 \pm 0.21^{\dagger \dagger}$ & $4.93 \pm 0.26^{*,+\dagger}$ \\
CT-NLC $4 \mathrm{mg} / \mathrm{kg}$ & $1.93 \pm 0.14^{*, t \dagger}$ & $4.70 \pm 0.37^{* *, \dagger \dagger}$ \\
CT-NLC 2 $\mathrm{mg} / \mathrm{kg}$ & $1.99 \pm 0.19^{*, t \dagger}$ & $4.88 \pm 0.30^{*,+\dagger}$ \\
\hline
\end{tabular}

Notes: Data represent the mean \pm standard deviation. ${ }^{* P}<0.05 ; * * P<0.01$ compared with control; $\because+P<0.01$ compared with cyclophosphamide.

Abbreviations: T-NLC, tripterine-loaded nanostructured lipid carriers; CT-NLC, cell-penetrating peptide-coated T-NLC.

\section{Histopathologic examination}

As shown in Figure 6, normal tumor cell nuclei were stained blue violet and the extracellular matrix and cytoplasm were stained dark pink, while necrotic cells were stained light pink, as indicated by the black arrows. It can be seen that the tumor cells retained their heteromorphism, including an irregular shape, enlarged and darker stained nuclei, and nuclear atypia. Marked tumor cell necrosis was seen in the drug-treated groups, with areas of tissue necrosis significantly increased in the following order: CT-NLC group > T-NLC group $>$ free tripterine group at the same doses. As seen in the CT-NLC group, there was extensive patchy and punctiform cellular necrosis, and the extent of necrosis in the low-dose CT-NLC group was much higher than that in the high-dose free tripterine group.

\section{Apoptosis detection in tumor cells by TUNEL assay}

As shown in Figure 7, the TUNEL assay revealed statistically significant differences between the drug groups and the control group $(P<0.05)$ and also between the CT-NLC group and the other two drug groups $(P<0.01)$. Apoptotic nuclei were stained dark brown and more apoptotic tumor cells were found in the cyclophosphamide, CT-NLC, and T-NLC groups than in the free tripterine and control groups. The AI followed the order of cyclophosphamide $>$ CT-NLC $>$ T- 

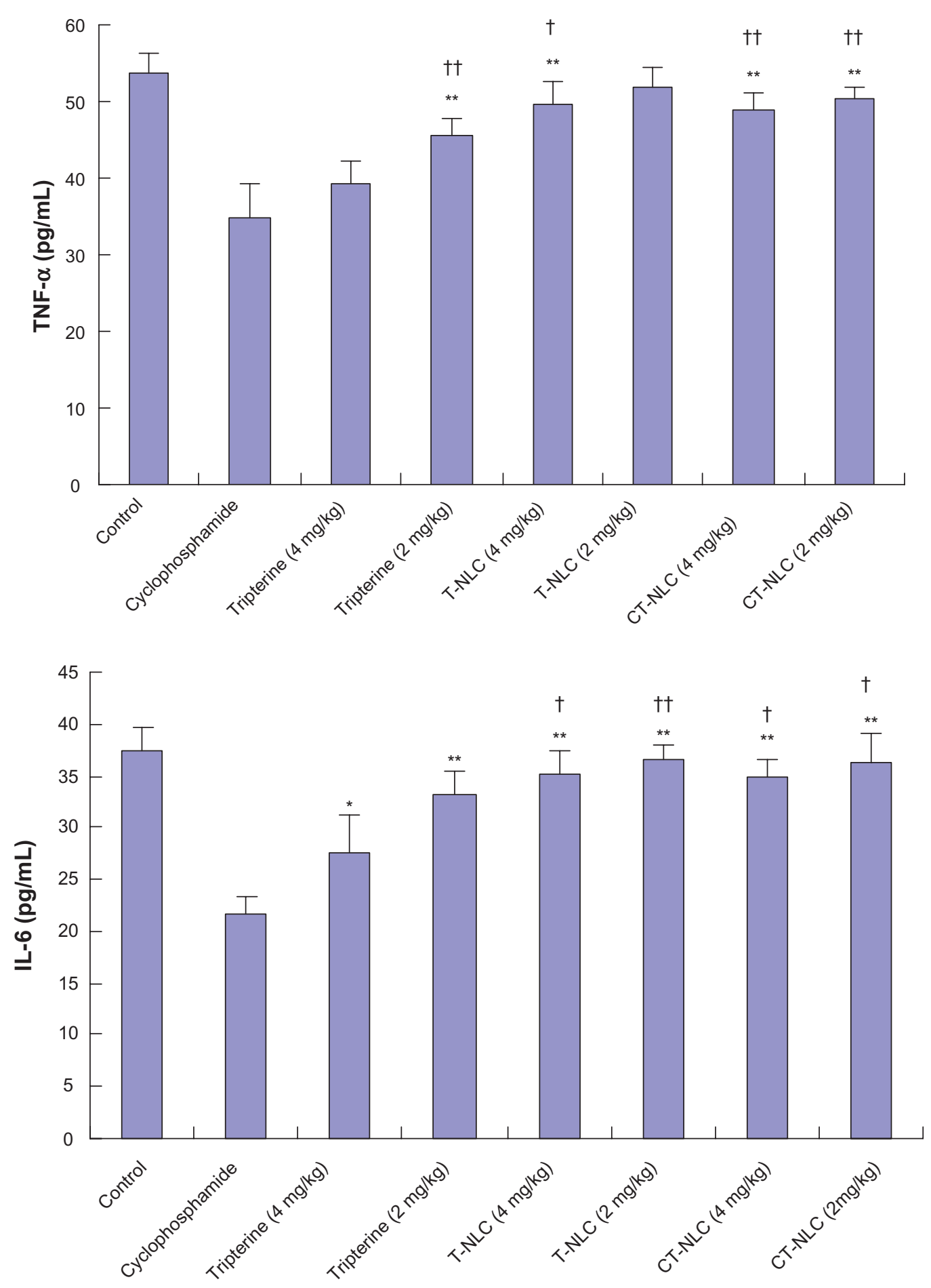

Figure 5 Comparison of serum TNF- $\alpha$ and IL-6 levels after I 4 days of treatment.

Notes: Data represent the mean \pm standard deviation $(n=6)$. $* P<0.05 ; * * P<0.0$ I versus cyclophosphamide; ${ }^{\dagger} P<0.05$; ${ }^{t \dagger} p<0.0$ I versus tripterine 4 mg/kg.

Abbreviations: T-NLC, tripterine-loaded nanostructured lipid carriers; CT-NLC, cell-penetrating peptide-coated T-NLC; TNF- $\alpha$, tumor necrosis factor alpha; IL-6, interleukin 6.

NLC $>$ free tripterine. According to Figure 7I, the AI in the CT-NLC group was $14.15 \% \pm 2.35 \%$ versus $12.08 \% \pm 1.94 \%$ in the T-NLC group $(P<0.05), 6.07 \% \pm 0.71 \%$ in the $4 \mathrm{mg} / \mathrm{kg}$ free tripterine group $(P<0.01)$, and $1.14 \% \pm 0.46 \%$ in the saline control group $(P<0.01)$.

\section{Discussion}

In a previous publication, we reported successful construction of CT-NLC and demonstrated the effect of CT-NLC with regard to increasing the intestinal absorption and oral bioavailability of tripterine. ${ }^{24}$ In the present study, we evaluated 

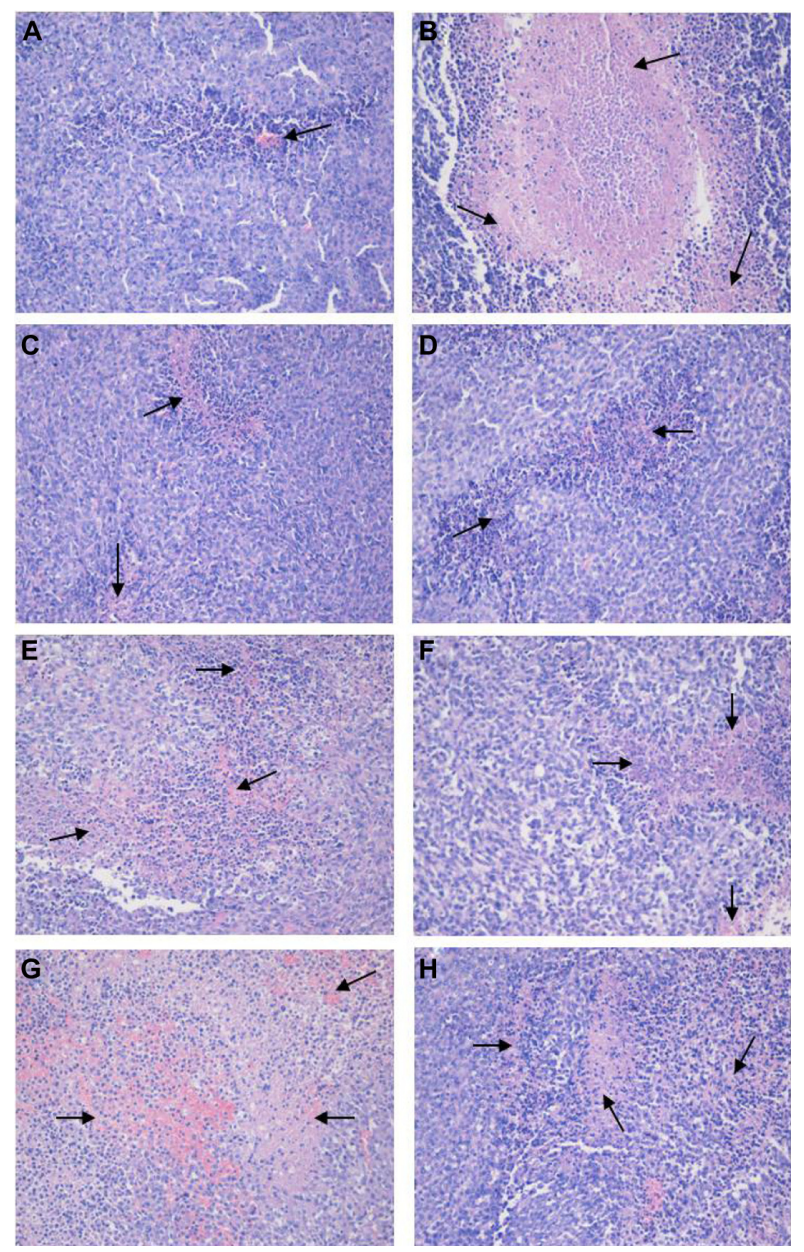

Figure 6 H\&E staining of tumor sections. Representative images on H\&E staining for (A) saline control group, (B) cyclophosphamide group, (C) free tripterine $4 \mathrm{mg} / \mathrm{kg}$ suspension group, (D) free tripterine $2 \mathrm{mg} / \mathrm{kg}$ suspension group, (E) T-NLC $4 \mathrm{mg} / \mathrm{kg}$ group, (F)T-NLC $2 \mathrm{mg} / \mathrm{kg}$ group, (G) CT-NLC $4 \mathrm{mg} / \mathrm{kg}$ group, and (H) CT-NLC $2 \mathrm{mg} / \mathrm{kg}$ group are shown. Necrotic cells are marked by black arrows. Magnification 200x.

Abbreviations: T-NLC, tripterine-loaded nanostructured lipid carriers; CT-NLC, cell-penetrating peptide-coated T-NLC; H\&E, hematoxylin and eosin.

the antitumor efficacy of CT-NLC in prostate tumor cells in vitro and in vivo.

Tripterine, a triterpene compound, is known to inhibit proliferation of a variety of tumor cells, including U937 cells, human prostate cancer cell lines, HL-60 cells, and human melanoma cells. ${ }^{25}$ In the present study, MTT assay results indicated that CT-NLC could enhance the antiproliferative effect of tripterine in PC-3 and RM-1 cells in a dose-dependent manner. In terms of $\mathrm{IC}_{50}$, both CT-NLC and T-NLC had a more remarkable inhibitory effect on the proliferation of PC-3 and RM-1 cells than did the tripterine suspension. Moreover, tripterine formulated in CT-NLC showed higher cytotoxicity, hypothesized to occur as follows: CT-NLC with a small size of around $100-150 \mathrm{~nm}$ are preferentially accumulated in tumors due to the enhanced permeability and retention (EPR) effect in highly fenestrated tumor endothelial cells with poor extravasation from normal vasculature; ${ }^{26}$ with the high positive charge density conferred by CPP, uptake of CT-NLC by tumor cells might be enhanced by electrostatic interactions between CPP and the negatively charged cell surface; ${ }^{27}$ and translocation of CPP across the cell membrane by CT-NLC via endocytosis or direct penetration may enhance intracellular drug accumulation. ${ }^{28}$

In order to investigate the antitumor activity of CT-NLC further in vivo, we constructed a mouse model of prostate cancer using RM-1 cells. As seen in the tumor volume changes, both CT-NLC and T-NLC achieved more effective inhibition of tumor growth, with high-dose CT-NLC showing the strongest antitumor effect. We also found that the tumor inhibition rate was much greater in mice treated with CT-NLC and T-NLC at low doses $(2 \mathrm{mg} / \mathrm{kg})$ than in mice treated with free tripterine at a high $(4 \mathrm{mg} / \mathrm{kg})$ dose $(P<0.05)$, especially in the CT-NLC group. The higher antitumor activity of CT-NLC and T-NLC may be attributable to the following: the structure of NLC, which contains a liquid and solid lipid core, could increase the solubility and stability of tripterine and improve its oral absorption; ${ }^{29}$ the optimal particle size of NLC could enhance the accumulation and penetration of tripterine into the tumor area via the EPR effect; ${ }^{26}$ and tripterine, released slowly from NLC, would be maintained at a constant concentration for a relatively long period in vivo, thereby having consistent antitumor efficacy. Further, Ste- $\mathrm{R}_{6} \mathrm{~L}_{2}$ (a type of CPP composed mainly of arginine and leucine) could confer a positive charge to the nanoparticles. Taken together, the major mechanism accounting for the superiority of CT-NLC over T-NLC and free tripterine may involve the positive charge density of CT-NLC having high electrostatic interaction with the negatively charged tumor cell surface and CPP mediating intracellular nanoparticle delivery via both endocytic and nonendocytic pathways.

It should be pointed out that tripterine is known for its toxicity and side effects. Analysis of variations in animal body weight can be used to evaluate the adverse effects of different therapy regimens. Significant weight loss was found in the free tripterine group at high doses, while weight gain occurred in the formulation groups during treatment. These results suggest that CT-NLC and T-NLC may be less toxic to mice than free tripterine. Sustained release of tripterine from NLC in a controlled manner could avoid the effects of high concentrations of free drug in normal cells and tissue, thereby reducing the toxicity. Moreover, the accumulation and penetration of NLC in tumor tissue via the EPR effect 

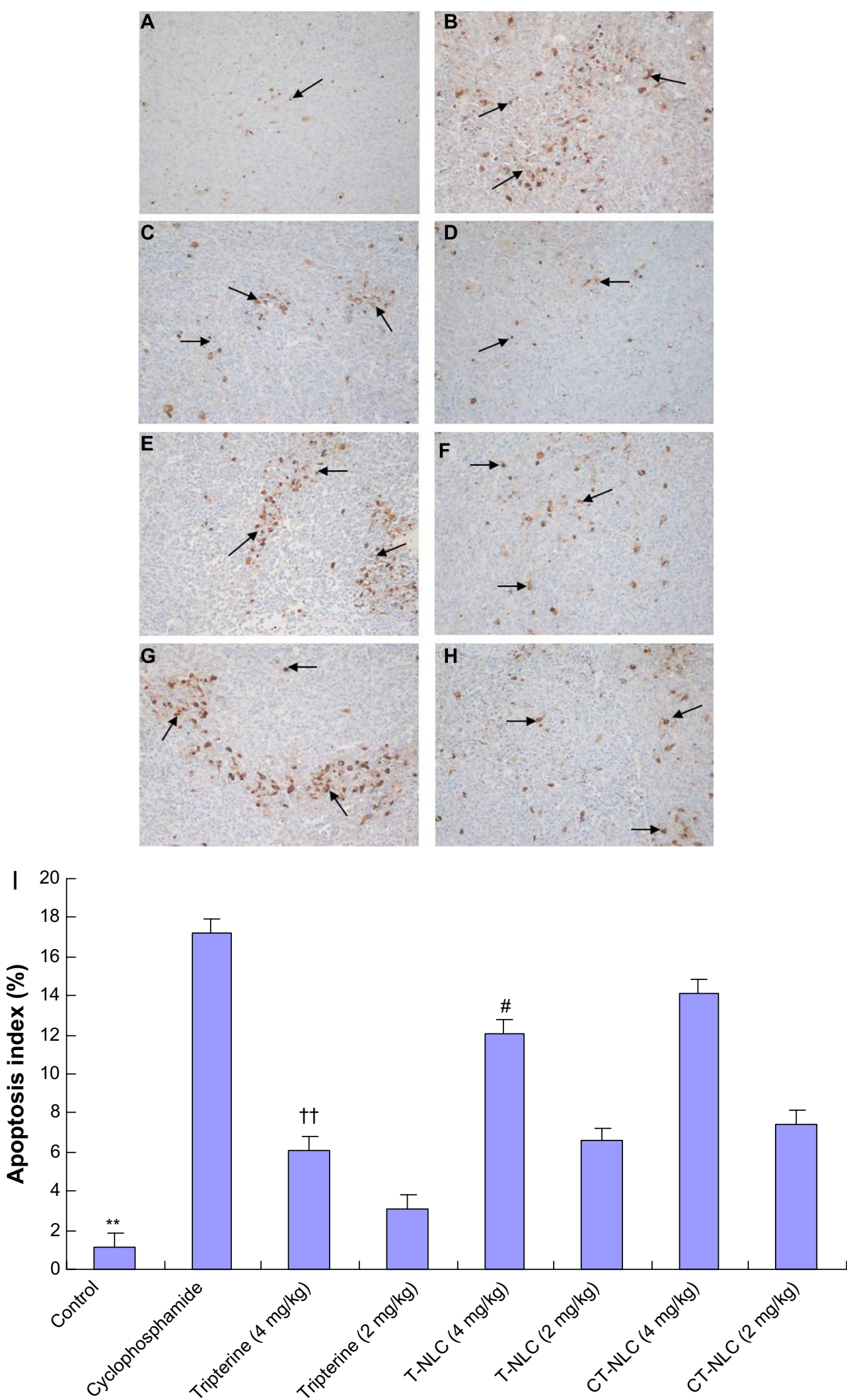

Figure 7 Effects of CT-NLC on tumor apoptosis. Representative images of TUNEL staining for (A) saline control group, (B) cyclophosphamide group, (C) tripterine suspension group $4 \mathrm{mg} / \mathrm{kg}$, (D) tripterine suspension group $2 \mathrm{mg} / \mathrm{kg}$, (E) T-NLC group $4 \mathrm{mg} / \mathrm{kg}$, (F)T-NLC group $2 \mathrm{mg} / \mathrm{kg}$, (G) CT-NLC group $4 \mathrm{mg} / \mathrm{kg}$, and (H) CT-NLC group $2 \mathrm{mg} / \mathrm{kg}$ are shown. Positive cells marked by black arrows. Magnification 400x. The apoptosis index is shown as a percentage of TUNEL-positive cells (I).

Notes: Data represent the mean \pm standard deviation $(n=6)$. $* * P<0.0$ I versus control; ${ }^{+t} P<0.0$ l versus tripterine $4 \mathrm{mg} / \mathrm{kg}$; ${ }^{\sharp} P<0.05 \mathrm{versus} \mathrm{T-NLC} 4 \mathrm{mg} / \mathrm{kg}$.

Abbreviations: T-NLC, tripterine-loaded nanostructured lipid carriers; CT-NLC, cell-penetrating peptide-coated T-NLC; TUNEL, terminal deoxynucleotidyl transferase (TdT)-mediated dUTP nick end labeling. 
would result in a higher NLC concentration in tumor tissue than in normal tissue, and such specific biodistribution of NLC could also decrease the toxicity of tripterine in normal cells and tissues. Therefore, it is expected that CT-NLC and T-NLC would have a favorable safety profile.

Our results for spleen and thymus index determination indicate that tripterine could inhibit immune function via its immunosuppressive action. Nevertheless, CT-NLC and T-NLC had less significant immunosuppressive activity than free tripterine. To evaluate the potential immunomodulatory activities of CT-NLC, an enzyme-linked immunosorbent assay was performed to assess the production of cytokines (TNF- $\alpha$ and IL-6) relevant to antitumor immunity. The data indicate that IL- 6 and TNF- $\alpha$ levels were both significantly decreased by free tripterine, and cyclophosphamide owing to their immunosuppression, but dramatically enhanced by CT-NLC and T-NLC. The reduced IL- 6 and TNF- $\alpha$ expression detected in the free tripterine and cyclophosphamide groups was due to their immunosuppression. However, as a potent drug vehicle, NLC can accumulate tripterine at tumor sites, reduce immunosuppression in a mouse model, and prolong mouse survival time by entrapping and controlling drug release.

H\&E histology and TUNEL staining of the excised tumor sections were carried out to investigate necrosis and apoptosis in the tumor tissue. The images of tumor tissue sections stained by H\&E showed that the most tumor cell necrosis occurred in the CT-NLC group, providing substantial evidence for the efficient antitumor activity of CT-NLC in vivo. It has been reported that tripterine preferentially inhibits the chymotrypsin-like activity of the $26 \mathrm{~S}$ proteasome, and induces apoptosis in both in vitro and in vivo prostate cancer models. ${ }^{30,31}$ TUNEL analysis revealed that treatment with tripterine and its formulations could induce apoptotic death in prostate tumor cells, and more apoptotic cells (with brown nuclei) were observed in the CT-NLC and T-NLC groups than in the free tripterine group at the same dosage. The AI of the CT-NLC group (4 mg/kg) was 2.33-fold and 1.17-fold higher than that in the free tripterine and T-NLC groups $(4 \mathrm{mg}$ / $\mathrm{kg}$ ). The stronger necrosis-inducing and apoptosis-inducing effects of CT-NLC may have been associated with better oral absorption in the gastrointestinal tract and the EPR effect, together with the CPP, which enhanced the penetration of CT-NLC into the tumor cell membrane and their selective accumulation in tumor cells.

\section{Conclusion}

In this study, we demonstrated that CT-NLC effectively suppressed proliferation of PC-3 and RM-1 cells in vitro in a dose-dependent manner. Further, CT-NLC showed significantly enhanced antitumor activity and fewer side effects in a mouse model of prostate cancer. Moreover, the present data indicate that CT-NLC is a potent drug vehicle that is able to target tumor tissues and suppress prostate tumor growth by inducing cell necrosis and apoptosis. In addition to nanoparticles, CPPs represent another class of promising carrier molecule candidates for delivery of NLC and their payloads into tumor cells. This CPP-based nanoparticle delivery system may be a potential treatment for cancer.

\section{Acknowledgments}

This work was supported financially by the Natural Science Foundation of Jiangsu Province (BK2010593) and the Jiangsu Provincial Chinese Medicine Leading Talent Project (LJ200913).

\section{Disclosure}

The authors report no conflicts of interest in this work.

\section{References}

1. Kannaiyan R, Shanmugam MK, Sethi G. Molecular targets of celastrol derived from thunder of god vine: potential role in the treatment of inflammatory disorders and cancer. Cancer Lett. 2011;303(1):9-20.

2. Liu XP, Zhou ST, Li XY, et al. Antitumor activity of N-trimethyl chitosan-encapsulated camptothecin in a mouse melanoma model. J Exp Clin Cancer Res. 2010;29:76

3. Guo QL, You QD, Wu ZQ, Yuan ST, Zhao L. General gambogic acids inhibited growth of human hepatoma SMMC-7721 cells in vitro and in nude mice. Acta Pharmacol Sin. 2004;25(6):769-774.

4. Jang SY, Jang SW, Ko J. Celastrol inhibits the growth of estrogen positive human breast cancer cells through modulation of estrogen receptor $\alpha$. Cancer Lett. 2011;300(1):57-65.

5. Mou H, Zheng Y, Zhao P, et al. Celastrol induces apoptosis in nonsmall-cell lung cancer A549 cells through activation of mitochondriaand Fas/FasL-mediated pathways. Toxicol In Vitro. 2011;25(5): $1027-1032$.

6. Rajendran P, Li F, Shanmugam MK, et al. Celastrol suppresses growth and induces apoptosis of human hepatocellular carcinoma through the modulation of STAT3/JAK2 signaling cascade in vitro and in vivo. Cancer Prev Res (Phila). 2012;5(4):631-643.

7. Ge P, Ji X, Ding Y, et al. Celastrol causes apoptosis and cell cycle arrest in rat glioma cells. Neurol Res. 2010;32(1):94-100.

8. Lee JH, Won YS, Park KH, et al. Celastrol inhibits growth and induces apoptotic cell death in melanoma cells via the activation ROS-dependent mitochondrial pathway and the suppression of PI3K/AKT signaling. Apoptosis. 2012;17(12):1275-1286.

9. Dai Y, DeSano J, Tang W, et al. Natural proteasome inhibitor celastrol suppresses androgen-independent prostate cancer progression by modulating apoptotic proteins and NF-kappaB. PLoS One. 2010;5(12): e14153.

10. Liu Z, Ma L, Zhou GB. The main anticancer bullets of the Chinese medicinal herb, thunder god vine. Molecules. 2011;16(6):5283-5297.

11. Liu D, Liu Z, Wang L, Zhang C, Zhang N. Nanostructured lipid carriers as novel carrier for parenteral delivery of docetaxel. Colloids Surf B Biointerfaces. 2011;85(2):262-269.

12. Das S, Chaudhury A. Recent advances in lipid nanoparticle formulations with solid matrix for oral drug delivery. AAPS PharmSciTech. 2011;12(1):62-76. 
13. Des Rieux A, Fievez V, Momtaz M, et al. Helodermin-loaded nanoparticles: characterization and transport across an in vitro model of the follicle-associated epithelium. J Control Release. 2007;118(3): 294-302.

14. Hayashi Y, Yamauchi J, Khalil IA, Kajimoto K, Akita H, Harashima H. Cell penetrating peptide-mediated systemic siRNA delivery to the liver. Int J Pharm. 2011;419(1-2):308-313.

15. Juliano RL, Alam R, Dixit V, Kang HM. Cell-targeting and cell-penetrating peptides for delivery of therapeutic and imaging agents. Wiley Interdiscip Rev Nanomed Nanobiotechnol. 2009;1(3): 324-335.

16. Furukawa R, Yamada Y, Takenaga M, Igarashi R, Harashima H. Octaarginine-modified liposomes enhance the anti-oxidant effect of lecithinized superoxide dismutase by increasing its cellular uptake. Biochem Biophys Res Commun. 2011;404(3):796-801.

17. Fotin-Mleczek M, Fischer R, Brock R. Endocytosis and cationic cellpenetrating peptides - a merger of concepts and methods. Curr Pharm Des. 2005;11(28):3613-3628.

18. Duchardt F, Fotin-Mleczek M, Schwarz H, Fischer R, Brock R. A comprehensive model for the cellular uptake of cationic cellpenetrating peptides. Traffic. 2007;8(7):848-866.

19. Tyagi M, Rusnati M, Presta M, Giacca M. Internalization of HIV-1 that requires cell surface heparan sulfate proteoglycans. J Biol Chem. 2001;276(5):3254-3261.

20. Yezhelyev MV, Qi L, O’Regan RM, Nie S, Gao X. Proton-sponge coated quantum dots for siRNA delivery and intracellular imaging. J Am Chem Soc. 2008;130(28):9006-9012.

21. Rothbard JB, Garlington S, Lin Q, et al. Conjugation of arginine oligomers to cyclosporin A facilitates topical delivery and inhibition of inflammation. Nat Med. 2000;6(11):1253-1257.
22. Schwarze SR, Ho A, Vocero-Akbani A, Dowdy SF. In vivo protein transduction: delivery of a biologically active protein into the mouse. Science. 1999;285(5433):1569-1572.

23. Liu J, Li H, Chen D, et al. In vivo evaluation of novel chitosan graft polymeric micelles for delivery of paclitaxel. Drug Deliv. 2011;18(3): 181-189.

24. Chen Y, Yuan L, Zhou L, Zhang ZH, Cao W, Wu Q. Effect of cellpenetrating peptide-coated nanostructured lipid carriers on the oral absorption of tripterine. Int J Nanomedicine. 2012;7:4581-4591.

25. Li Z, Wu X, Li J, et al. Antitumor activity of celastrol nanoparticles in a xenograft retinoblastoma tumor model. Int J Nanomedicine. 2012;7: 2389-2398.

26. Kohane DS. Microparticles and nanoparticles for drug delivery. Biotechnol Bioeng. 2007;96(2):203-209.

27. Hirose H, Takeuchi T, Osakada H, et al. Transient focal membrane deformation induced by arginine-rich peptides leads to their direct penetration into cells. Mol Ther. 2012;20(5):984-993.

28. Ziegler A. Thermodynamic studies and binding mechanisms of cellpenetrating peptides with lipids and glycosaminoglycans. Adv Drug Deliv Rev. 2008;60(4-5):580-597.

29. González-Mira E, Nikolić S, García ML, Egea MA, Souto EB, CalpenaAC. Potential use of nanostructured lipid carriers for topical delivery of flurbiprofen. J Pharm Sci. 2011;100(1):242-251.

30. Zhang T, Hamza A, Cao X, et al. A novel Hsp90 inhibitor to disrupt Hsp90/Cdc37 complex against pancreatic cancer cells. Mol Cancer Ther. 2008;7(1):162-170.

31. Yang H, Chen D, Cui QC, Yuan X, Dou QP. Celastrol, a triterpene extracted from the Chinese "Thunder of God Vine," is a potent proteasome inhibitor and suppresses human prostate cancer growth in nude mice. Cancer Res. 2006;66(9):4758-4765.
International Journal of Nanomedicine

\section{Publish your work in this journal}

The International Journal of Nanomedicine is an international, peerreviewed journal focusing on the application of nanotechnology in diagnostics, therapeutics, and drug delivery systems throughout the biomedical field. This journal is indexed on PubMed Central, MedLine, CAS, SciSearch ${ }^{\circledR}$, Current Contents ${ }^{\circledR} /$ Clinical Medicine,

\section{Dovepress}

Journal Citation Reports/Science Edition, EMBase, Scopus and the Elsevier Bibliographic databases. The manuscript management system is completely online and includes a very quick and fair peer-review system, which is all easy to use. Visit http://www.dovepress.com/ testimonials.php to read real quotes from published authors. 